\section{ARTICLE}

Gareth Clancy and Peter Stam Office for National Statistics

\section{SUMMARY}

Unemployment and the claimant count are both important measures of spare labour capacity in the UK economy. However, they each record subtly different aspects of the non-utilisation of labour. Unemployment estimates are based on a person's self-classification as being 'out of work, but 'currently and actively seeking to work' in the Labour Force Survey (LFS), while the claimant count is a count of the number of people who claim unemployment related benefits (the majority of whom claim Jobseeker's allowance (JSA)). This article examines the reasons that the two measures provide different estimates, and presents analysis on the groups of people that make up the gap between unemployment and the claimant count. The article finds that the differences in definitions contribute to this gap, but there are also other reasons for the changing size of the gap.

\title{
Explaining the difference between unemployment and the claimant count
}

U sing headline statistics, unemployment derived from the Labour Force Survey (LFS) has been consistently higher than the claimant count measure of the number of people claiming unemployment-related benefits. There is a strong positive correlation between the two measures; that is they tend to show the same broad trends, rising and falling together across the economic cycle. However, since the recession in the early 1990s this relationship has not been as evident. This is shown in Figure 1, where the two series have diverged since 1994. Furthermore, a number of new and interesting relationships across different demographic groups are now present. In the past year these relationships have become ever more important as the gap (the difference between the levels of unemployment and claimant count) has changed.

ONS publishes a regular comparison of this difference in the Labour Market Overview (ONS (2010)), alongside the monthly Labour Market statistical bulletin. This article presents the definitions of the two statistical series, and provides comparisons using consistent time periods for broadly comparable age groups (unemployment levels for people aged 18$59 / 64$ years and the claimant count for people aged 18 years and over, see Box 1). ONS have also published an article (Clancy and Ker (2010)) which presented differences between unemployment and the claimant count by duration. Morris and Costello (2010) have analysed the differences between the two series for Wales, with a specific focus on providing guidance when looking at short term changes in unemployment.

Figure 1 shows the strong correlation mentioned previously, and the development of the gap between the two series. The size of the gap has fluctuated considerably over the period presented, both converging and diverging over time. During the 1980s and 1990s the gap between the two measures tended to narrow as unemployment and claimant count peaked, and widen as they reached a trough. It is noticeable that in 200910 , even though both measures have increased, the gap has not narrowed in the same way as previously.

In order to understand the reasons for any differences between the two measures, the definitions of unemployment and the claimant count need to be considered. Thorough definitions are provided in Box 2 but the main differences between the two definitions can be summarised as:

- the headline statistics tend to cover slightly different age groups

- people who are unemployed are not necessarily eligible for Jobseeker's Allowance (JSA), or may choose not to claim even when they are eligible (their own or partner's financial circumstances can influence this)

- people who are eligible for JSA may not fit the definition of unemployment (for example, it is possible to be employed or inactive while claiming JSA) 


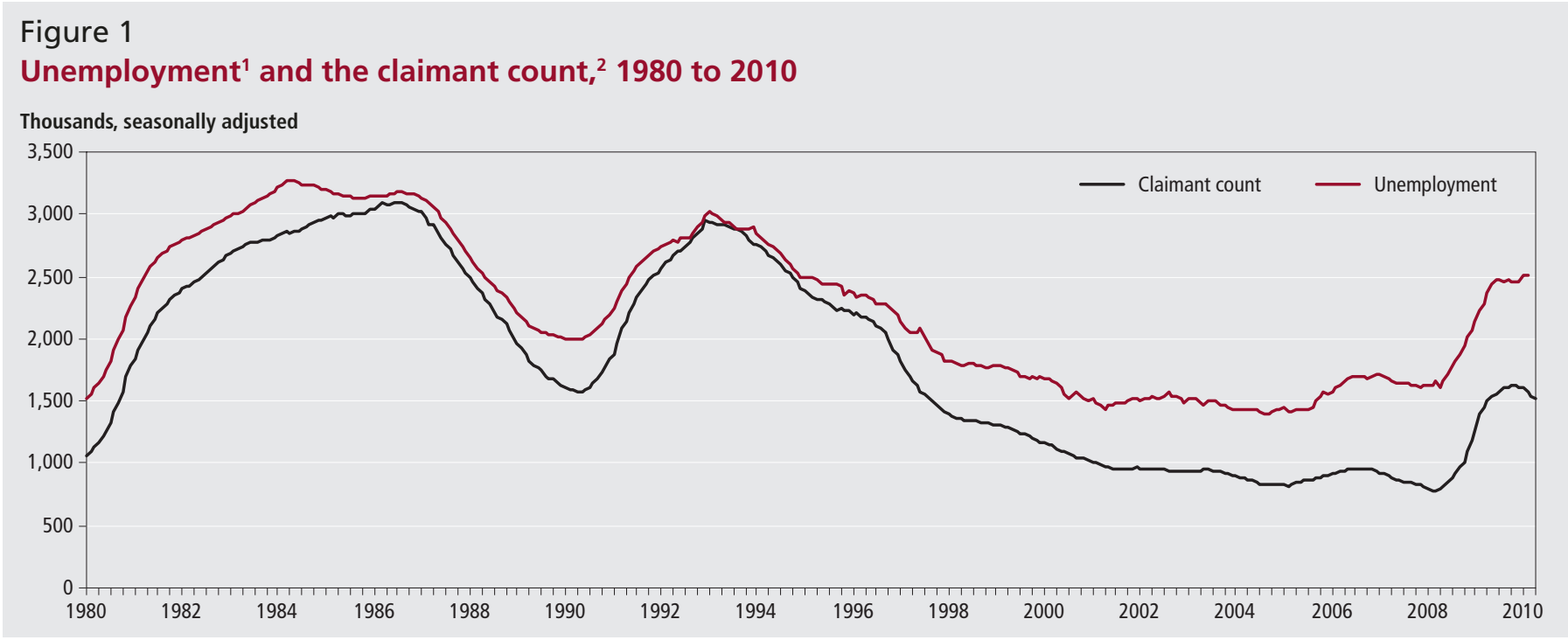

Notes:

Source: Labour Force Survey and Jobcentre Plus administrative system

1 Unemployment estimates are for people aged 16 years and over. This is consistent with the headline figures in the Labour Market statistic bulletin. Full time series data are available from January 1971.

2 Claimant count figures are provided for people aged 18 years and over. This is consistent with the headline figures produced for the Labour Market statistical bulletin. Full time series data are available from January 1971.

Box 1

\section{Presentation of unemployment and claimant count data in} this article

Estimates used in this article are not always placed on a comparable basis, for presentational purposes, or because not all series have the required time periods. To make the two series comparable unemployment levels are restricted to those people aged between 18 and State Pension Age (SPA) (and are therefore not consistent with the International Labour Organisation (ILO) definition). Claimant count figures are presented for people aged 18 and over (in line with official statistics). This is because people aged 16, 17 and over SPA are not commonly represented in the claimant count.

Figure 1 shows the unemployment and claimant count levels using the age groups provided in the headline statistics. This figure therefore includes the difference arising from the 16 to 17 age group. Although there are a notable number of 16 and 17 year olds who classify themselves as unemployed (close to 200,000), normally the number of people aged 16 or 17 years in the claimant count is very small. For this reason, presenting the two series on an aged 18 and over basis brings the two series closer together, but placing them both on an aged 16 and over basis does not.

The headline statistics also differ in terms of their treatment of people over the state pension age (SPA). People may still consider themselves unemployed in the LFS, but they are more likely to draw upon pension entitlements as opposed to unemployment benefits in this age group.

The final definitional difference between unemployment and the claimant count is related to the different time periods they cover. The LFS unemployment figures are compiled for a three month rolling period, for example the unemployment estimate published in May 2010 refers to the three month period January to March 2010. The claimant count figures published at the same time were based on an extract from the administrative database for the month of April 2010. In order to compare like with like, it is necessary to either: choose one month from the LFS (and introduce greater instability into that estimate); or take a three month average of the claimant count, as was done in Figure 2 (and lose the advantage of more recent data available from the claimant count).

\section{Unemployment and claimant count quarterly changes}

Figure 2 shows that, for most of the period presented the quarterly changes are similar, demonstrating how the two series are generally correlated over time. Since unemployment has been greater than the claimant count between 1998 and 2010, where quarterly changes in unemployment were greater than that of the claimant count, this means that the gap between the two increased. Where the claimant count quarterly change is above that of unemployment, the gap reduced.

\section{Examining the size of the difference}

Despite the difference in age groups, a great deal of analytical insight can be found from examining the headline statistics as they are published. As demonstrated in Figure 1, the two series have converged and diverged in the last thirty years. Up until 1998 this pattern of convergence and divergence appeared to be strongly associated with the economic circumstances prevalent in the UK economy. In the early 1980s, the UK economy experienced an economic recession, as it did again in the early 1990s. In both periods the difference between unemployment and the claimant count grew. Following each recession the difference reduced in the mid-1980s and mid-1990s. 


\section{Box 2}

\section{Definitions of unemployment and the claimant count Unemployment}

The official estimates of unemployment for the UK are provided by the Office for National Statistics. These are produced from the Labour Force Survey (LFS) according to the International Labour Organisation (ILO) definition of unemployment. This states that a person is unemployed if they:

- are without a job, want a job, have actively sought work in the last four weeks, and are able to start work within the next two weeks; or

- are out of work, have found a job and are waiting to start it in the next two weeks

Each respondent's status is determined by their responses to a number of questions about their labour market activity. Only those people whose answers indicate that they satisfy these conditions are included in the UK unemployment estimates, which are published monthly in the Labour Market statistical bulletin.

\section{Claimant count}

The Claimant count is a measure of the number of people claiming unemployment related benefits: Jobseeker's Allowance or National Insurance Credits (hereafter collectively referred to as 'JSA' or the claimant count). It is taken from the Jobcentre Plus administrative systems. Although these are commonly referred to as 'unemployment related benefits' there are circumstances where a person is not unemployed.

Differences between the claimant count and unemployment estimates can occur because it is possible to be unemployed, but not claim JSA:

- people who are unemployed may not be eligible to claim - to be eligible for contribution based JSA they must have made a minimum National Insurance contribution across the previous two years. To be eligible for income based (means tested) JSA they should not receive more than a particular level of income

- a person's income or savings may be too high. Alternatively, they may be in a married or non-married relationship, or a Civil Partnership and their partner earns more than a certain level of income or works more than 24 hours a week meaning they may not be eligible for JSA

- in most cases JSA claimants will be aged between 18 and state pension age - as unemployed people over the state pension age will normally choose to claim pension payments rather than JSA. In contrast unemployment estimates include all people aged 16 years and over

- full-time study can make someone ineligible for JSA - but they can be classified as unemployed

- some people may be unemployed, but claiming an out-ofwork benefit other than JSA

- finally, those who do satisfy the eligibility criteria will not necessarily choose to claim unemployment benefits

It is also possible to claim JSA, but not be counted as unemployed:

- if a person satisfies certain maximum income conditions they may be eligible to claim JSA while working for up to 16 hours per week. They are therefore employed, according to the ILO definition

- if a person has undertaken insufficient job search they may be classified as inactive, rather than unemployed

- it is also possible that a person may work full-time and claim JSA fraudulently

These differences mean that unemployment and the claimant count cannot be used inter-changeably and it is important to be clear which statistic is being discussed.

\section{Figure 2}

\section{Quarterly change in unemployment ${ }^{1}$ and claimant count, ${ }^{2} 1998$ to 2010}

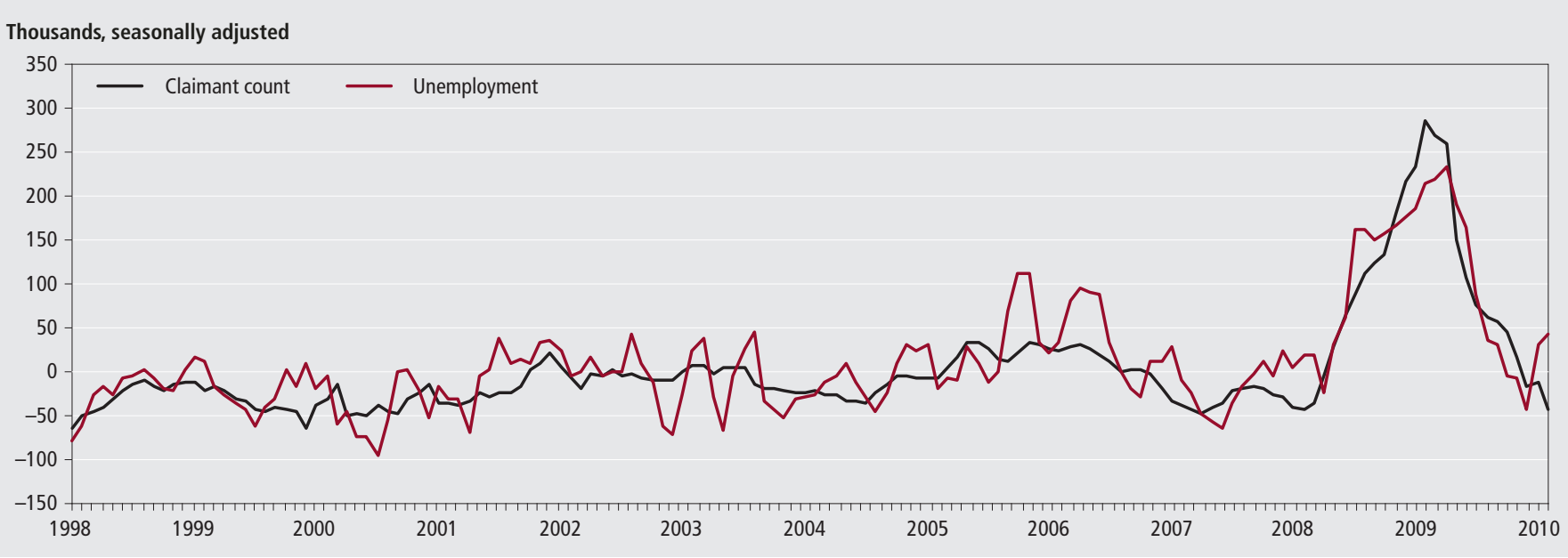

\section{Notes:}

Source: Labour Force Survey and Jobcentre Plus administrative system

1 Unemployment estimates are for people aged between 18 years and state pension age. These figures are not consistent with the headline figures produced for the Labour Market statistical bulletin. Data on this basis are available from July 1992.

2 Claimant count figures are provided for people aged 18 years and over. This is consistent with the headline figures produced for the Labour Market statistical bulletin. Full time series data are available from January 1971. 


\section{Figure 3 \\ Difference between headline unemployment ${ }^{1}$ and headline claimant count ${ }^{2}$ by sex (unemployment minus claimant count), 1980 to 2010}

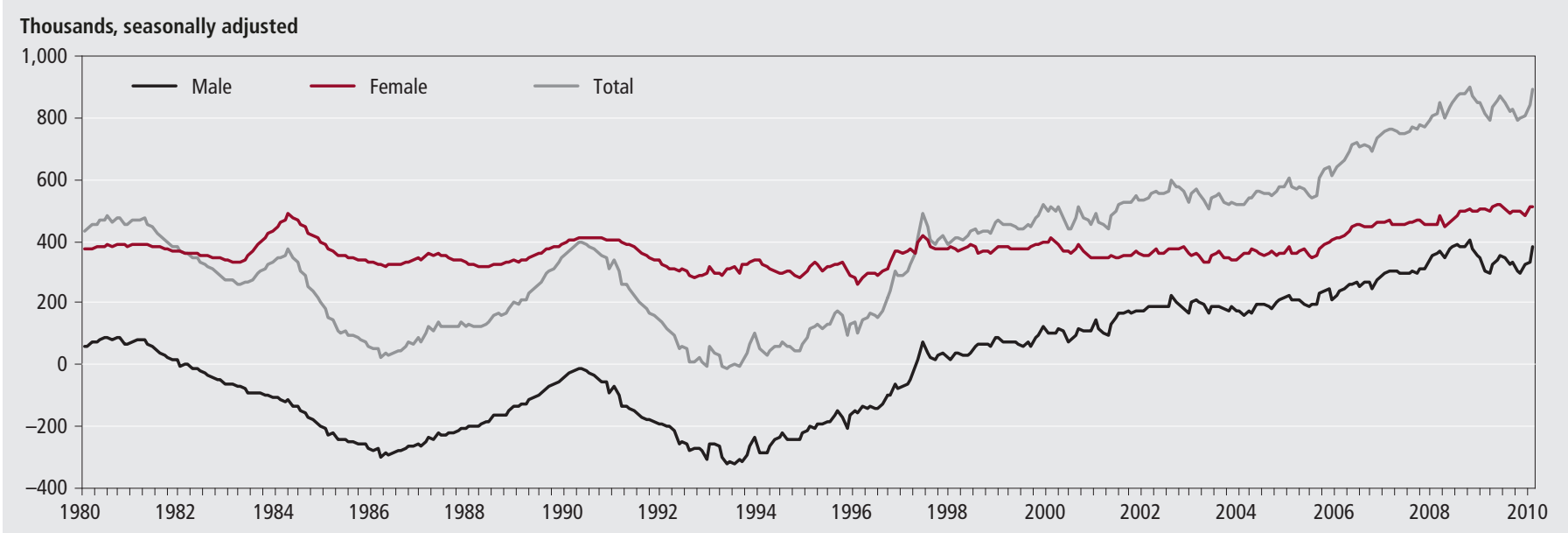

Notes:

Source: Labour Force Survey and Jobcentre Plus administrative system

1 Unemployment estimates are for people aged between 16 years and state pension age. These figures are not consistent with the headline figures produced for the Labour Market Statistical Bulletin. Full time series data are available from January 1971.

2 Claimant Count figures are provided for people aged 18 years and over. This is consistent with the headline figures produced for the Labour Market Statistical Bulletin. Full time series data are available from January 1971.

\section{Figure 4 \\ Difference between unemployment levels and the claimant count by age, sex, and full-time education}

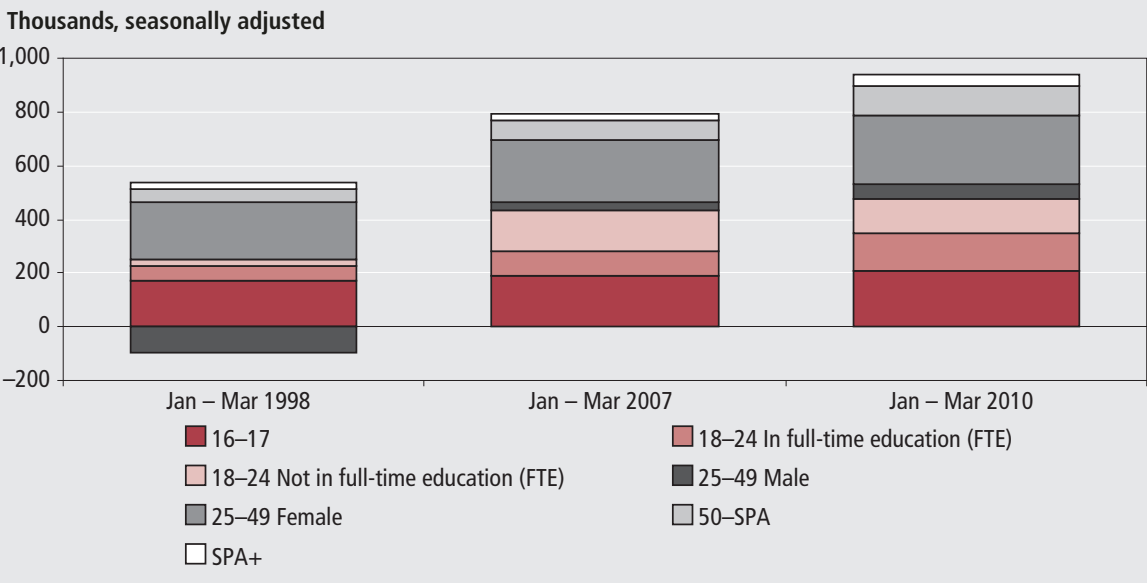

\section{Notes:}

Source: Labour Force Survey and Jobcentre Plus administrative system

1 This figure assumes that people aged 18-24 in full-time education, and those over state pension age are not eligible to claim JSA.

2 The three periods were chosen to capture the changes in the gap during the recent periods of economic growth in 1998 and 2007, and post 2008/09 recession.

Prior to the six quarters of economic contraction between Q2 2008 and Q3 2009, the UK economy had experienced over a decade of sustained economic growth. It is notable that in this period of economic growth the gap between unemployment and the claimant count grew (see Figure 3). By referring back to Figure 1 it can be surmised that the size of the difference was caused by the claimant count falling by more than unemployment levels.

\section{Differences by sex}

Figure 3 identifies the contributions that men and women have made to the gap.
The strong correlation between the total difference series and the 'Male' series is determined by the fact that men form a large proportion of unemployment (62 per cent in Jan-Mar 2010) and the claimant count (72 per cent in April 2010).

The 'Male' series highlights how the relationship between the two series has changed significantly over the period presented. During the late-80s and mid-90s the number of men claiming JSA exceeded the number declaring themselves unemployed in the LFS. This suggests that at the time there were a number of men claiming unemployment benefit who were either inactive or employed.

Figure 3 shows that up until 2006 the difference in unemployment and claimant count did not vary as much for women as it did for men. In fact the difference for women was close to 400,000 for most of the period 1980 to 2006. This positive gap suggests that throughout the period there were more unemployed women than there were in the claimant count. Furthermore, in the early and late 1990s there were short periods where the total difference was almost entirely made up by women (because the difference between men who were unemployed and men who were on the claimant count was zero). This indicates there was almost exactly the same number of men declaring themselves unemployed as there was in the claimant count.

\section{Differences by age}

The differences are explored more fully in Figure 4, which shows that people aged 16 and 17 years comprised a large proportion of the difference between unemployment and the claimant count in 1998. In the more recent periods presented, other areas have grown to make the younger age group form a smaller proportion of the difference.

It can also be seen in Figure 4 that in 1998 there were more men aged 25-49 in the claimant count than who declared themselves unemployed. This is shown by the negative contribution to the difference, which suggests that some men in the claimant count were either inactive or employed. In the two later periods the 


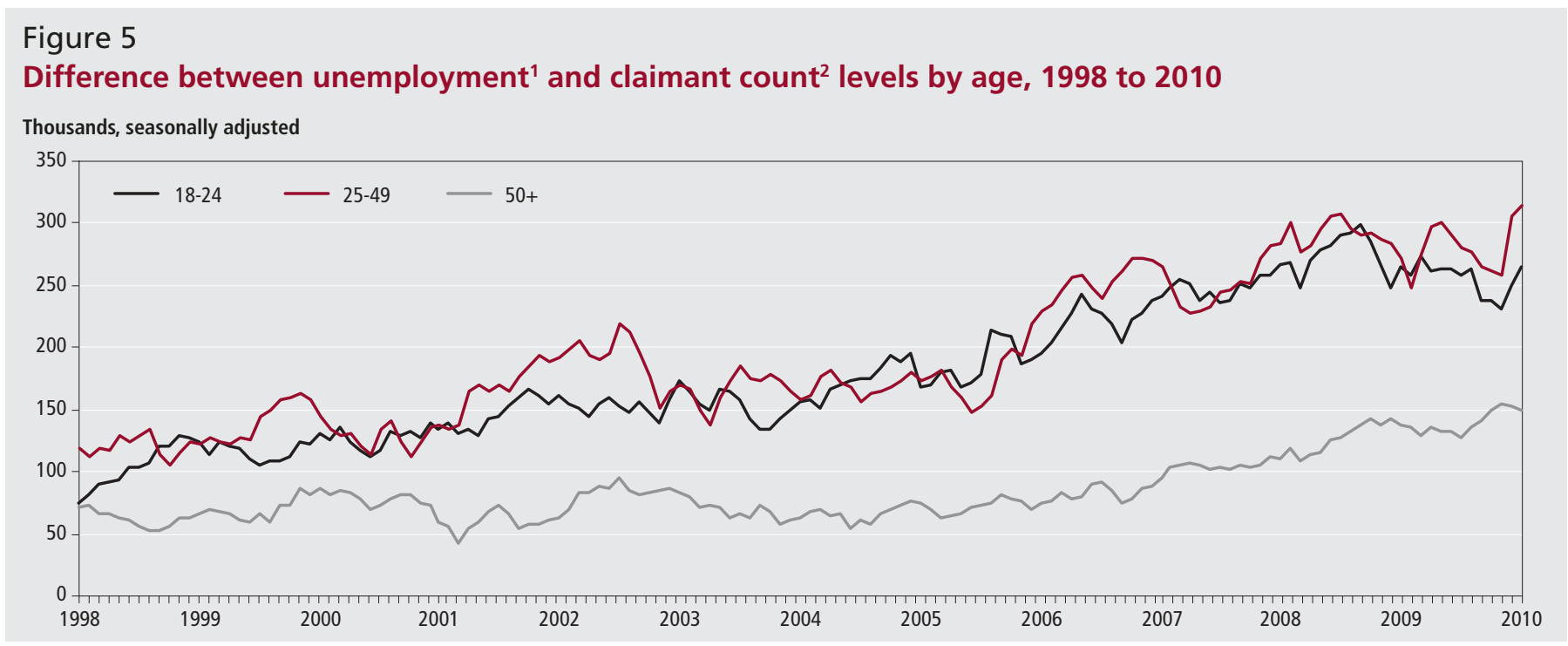

Notes:

Source: Labour Force Survey and Jobcentre Plus administrative system

1 Unemployment estimates are for people aged 18 years and over. These figures are not consistent with the headline figures produced for the Labour Market Statistical Bulletin. Data on this basis are available from July 1992.

2 Claimant Count figures are provided for people aged 18 years and over, consistent with the headline figures produced for the Labour Market Statistical Bulletin. Full time series data are available from January 1971.

difference for this group has become positive, changing this group from a net reducer of the gap to a net contributor to the gap.

Women aged 25-49 have consistently formed the largest part of the gap in terms of levels (comprising around 34 per cent of the gap in 1998). This fits with the fact that women represent a small proportion of the claimant count, and also that their eligibility to claim is often affected by their partner's income. The groups that have grown the most (in percentage terms) between 1998 and 2010 are people aged 18-24 (both in and not in full-time education) and men aged 25-49. The 'in full-time education' group has been influenced by increases in the number of students in the UK over the twelve years presented.

In addition to benefits designed to maintain a person's attachment to the labour market (like JSA) there are a number of other benefits provided by Government, which are not related to job seeking. These benefits can be described as 'inactive benefits', because they do not require economic activity, and include benefits for people who are sick or disabled as well as benefits related to children. The importance of these benefits is that claimants may be classified as unemployed according to their LFS responses, but because they do not claim JSA they are only included in unemployment. The magnitude of this can be demonstrated using the LFS, which shows that of everybody who stated they were claiming any type of benefit in January to March 2010, 42 per cent were claiming a benefit not related to job seeking (or an 'inactive benefit').
Figure 5 presents the difference between the claimant count and unemployment levels for three age bands. Between 1998 and 2004 the gap grew for people aged $18-24$ and $25-49$. The gap for the youngest age group (18-24) grew, from around 80,000 to 165,000 , meaning that there were more unemployed people than those in the claimant count. This corresponded with growth from 110,000 to 185,000 for people aged 25-49. In contrast, over the same period the gap for people aged between 50 and the SPA was comparatively stable, showing a small fall from 80,000 to 65,000 .

From 2004 the gaps for each of the three age groups experienced noticeable growth. Between 2004 and 2010 the gap increased for people aged $18-24$, reaching 266,000 for the three month period January to March 2010. This demonstrated an increase in the number of unemployed people in relation to the number of people in the claimant count. For the same three month period, people aged 25-49 contributed 315,000 - the highest of the three age groups presented. The gap also increased for people aged over 50 between 2004 and 2010. In January to March 2010 there were 150,000 more unemployed people than appeared in the claimant count.

The reasons for these changes are related to the changes shown in Figure 4. For example, the changes in the 25-49 age group are driven by the contribution to the gap made by men, because the contribution made by women aged $25-49$ is relatively stable (see Figure 3 and Figure 4). Looking at the 18-24 age group, Figure 4 showed that the contribution made by young people in full-time education grew over the period. There were also more unemployed people aged 18-24 who were not in full-time education than there were people aged 18-24 on the claimant count in 2010, than in 1998. However, the contribution made by this group to the gap was larger in 2007.

\section{Impact of migration}

During the past decade the number of foreign born and foreign nationals entering the UK labour market has increased (see Fix et al, 2009). Most recently the inflow of migrants has been driven by countries that acceded to the European Union in 2004, commonly known as the A8 countries (Czech Republic, Estonia, Hungary, Latvia, Lithuania, Poland, Slovakia and Slovenia). Different eligibility criteria for benefits apply to migrants from different parts of the world. However, in general migrants are more restricted in their access to unemployment benefits than citizens of the UK. This means that although in their responses in the LFS classify them as unemployed, a proportion of migrants are either not eligible for or do not claim JSA, and therefore increase the gap between the two measures. The extent to which this takes place is shown by the fact that according to the LFS, in January to March 2010, 45 per cent of unemployed people born in the UK claimed unemployment related benefits, whereas only 29 per cent of people born outside the UK claimed unemployment related benefits. Since A8 migrants to the UK have been predominantly young men (Drinkwater, Eade and Garapich, 2009), this will have 

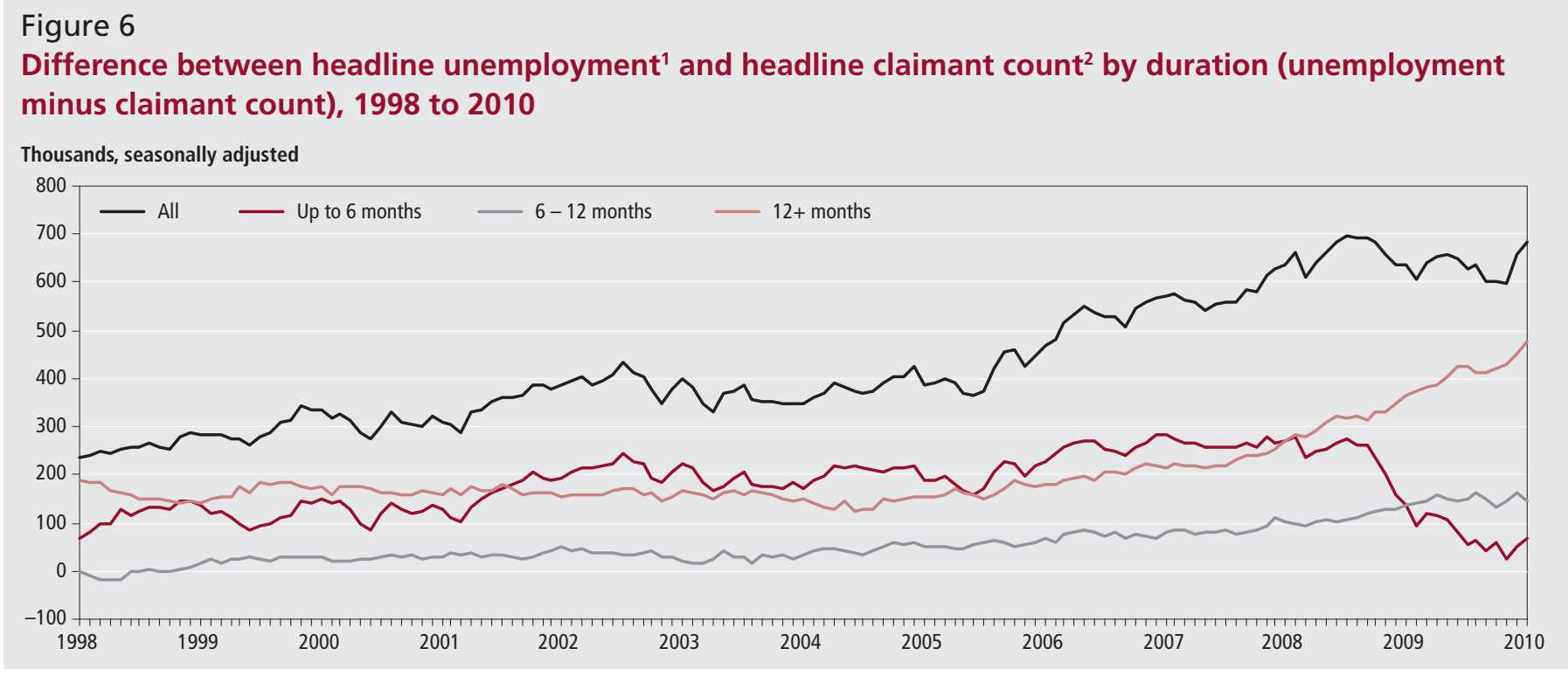

Notes:

Source: Labour Force Survey and Jobcentre Plus administrative system

1 Unemployment estimates are for people aged between 18 years and state pension age. These figures are not consistent with the headline figures produced for the Labour Market Statistical Bulletin. Data on this consistent basis are available from July 1992.

2 Claimant count figures are provided for people aged 18 years and over, consistent with the headline figures produced for the Labour Market Statistical Bulletin. Full time series data are available from January 1971.

contributed to the increases shown in

Figures 3 and 4 for these groups.

Differences according to duration

Figure 6 shows how these factors influence the difference between the two series. Between 1998 and 2005 the gap between the two series was predominantly caused by the 'up to 6 months' and ' $12+$ months' categories. From 2005 onwards, the differences between the number of unemployed people in the ' 6 to 12 months' and ' $12+$ months' categories, and their respective counterparts in the claimant count increased. At the end of 2008 the difference for the 'up to 6 months' category began to fall back towards 50,000 showing that the numbers of people unemployed and in the claimant count were 'more equal' in this group. At the same time the longest duration group (12+ months) became the main group driving the gap between the two series. This ' $12+$ months' series shows that fewer people have been in the claimant count for long periods relative to the numbers of people who have been classified as unemployed.

As set out in Clancy and Ker (2010), differences appear between the two series because being classified as unemployed or included in the claimant count can change over time. For example, it is only possible to claim some types of unemployment benefits continuously for a fixed period. With regards to unemployment, respondents in the LFS may report a duration of unemployment based on their total time out of work, rather than the time they have been 'ready and available' to work according to the ILO definition of unemployment. In addition, as stated earlier in this article, unemployed people who claim benefits that are not related to unemployment increase the gap between the claimant count and the unemployment estimates. This is particularly relevant to people who experience longer durations of unemployment, since some 'inactive' benefits are claimed as a result of long-term sickness or disability.

\section{People beginning and ending JSA claims (inflows and outflows)}

Figure 7 shows the net flows of people onto the claimant count register between 1989 and 2010. Periods where the series is positive depict the times when there were more people joining the claimant count than ending their claim period. The negative areas show where the number of people leaving the claimant count exceeded the number of people joining.

The period between 1992 and 2007 depicts a time period where the net flows were predominantly negative (more people leaving than joining the claimant count). The two large positive net flows in the early 1990s and between 2008 and 2009 are of interest because of the different path of the gap in these two periods. In the early 1990s a gap did appear between unemployment and the claimant count (unemployment being higher than the claimant count), but during the period 1990 to 1992 the gap converged again (see Figure 1). In the more recent economic downturn the gap between the two series was already established and has not shown any signs of reducing yet.

Figure 7 also provides an insight into 'short-term claimants', since by definition the people who have joined the claimant count have been there less than 6 months. The recent positive area in Figure 7 corresponds with the fall in the up to 6 months' series presented in Figure 6, suggesting that the reduction in this series was caused by the increase of inflows into the claimant count.

\section{Conclusion}

During the last decade new dynamics have appeared between unemployment and the claimant count. This article has shown how unemployment statistics produced from the LFS and the claimant count can be used to identify particular groups that have affected this change.

The most obvious reason for the gap is the differences in definitions: where one group of people are included in unemployment, but not the claimant count. The 16 and 17 year old group is one example of this (another being people above State Pension Age). A more subtle, but important difference is the timing of the two sources, with unemployment being produced on a rolling quarterly basis, and the claimant count on a monthly basis.

Figure 4 showed that since 1998 there have been a number of changes in particular demographic groups which have affected the size of the difference. Men aged 25-49 have become positive net contributors to 


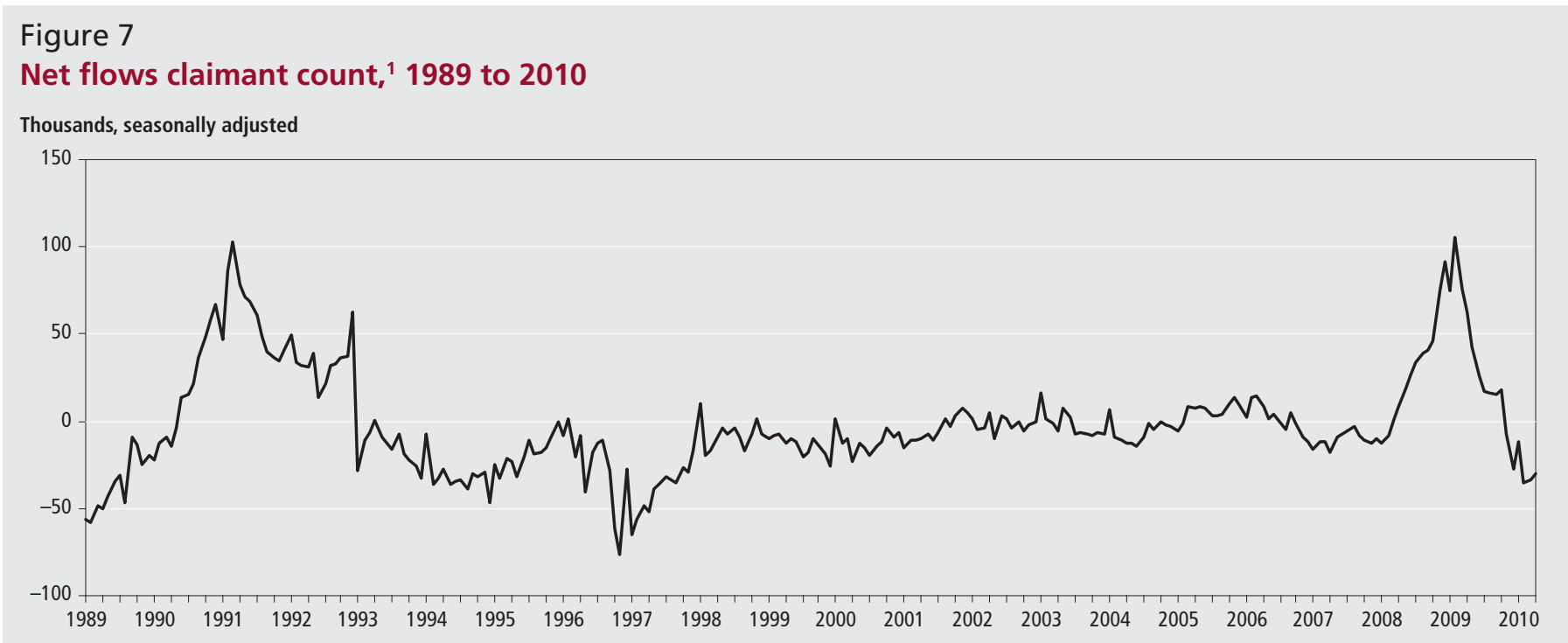

Note:

Source: Jobcentre Plus administrative system

1 Claimant count figures are provided for people aged 18 years and over, consistent with the headline figures produced for the Labour Market Statistical Bulletin. Data on the flows into and out of the Claimant Count are available from November 1988.

the difference, whereas previously they reduced the size of the gap. Also, the difference between unemployment and the claimant count has grown noticeably for people aged 18-24; both for those in full-time education and those not in full-time education. However, women aged 25-49 have continued to be the group who have contributed the most to the gap. The difference for each of these groups will be as a result of both increases in the numbers of JSA claimants who are not unemployed (inactive or employed), but also an increase in the number of unemployed people who do not claim JSA.

Since 2008 the increase in unemployment levels has introduced a new dynamic to the gap. There are now more long-term unemployed than there are long-term claimants. This fits with both eligibility to remain in the claimant count and the likely self-reporting bias introduced by people recalling their time out of work when responding to the LFS rather than their period of unemployment.

In this article the headline statistics for both unemployment and the claimant count have been used to show how factors outside of definitional differences have contributed to the changing size of the gap between the two series. Different growth rates for unemployment in relation to the claimant count by sex, age and length of time (duration) in either state have all been shown to be important.

\section{ACKNOWLEDGEMENTS}

The authors would like to thank Jessica Coleman and Daniel Ker for their assistance in producing the article, and Bob Watson and Simon Wood for the comments they provided.

\section{CONTACT}

almr@ons.gov.uk

\section{REFERENCES}

Clancy G and Ker D (2010) 'Labour Force Survey unemployment and benefits durations' Economic \& Labour Market Review, vol 4, no 04, pp 20-31.

Drinkwater S, Eade J and Garapich M (2009) 'Poles Apart? EU enlargement and the labour market outcomes of immigrants in the UK', International Migration , 47 (1), 161-90.

Fix M, Papademetriou D, Batalova J, Terrazas A, Lin S and Mittelstadt M (2009) 'Migration and the Global Recession', Migration Policy Institute.

Morris J and Costello J (2010) 'Differences between Claimant Count and Unemployment'. Available from: www.wales.gov.uk/statistics.

ONS (2010). Labour Market Overview: May 2010. Available from:

www.statistics.gov.uk/downloads/theme_ labour/LMS_QandA.pdf 